\title{
Erratum to: Cervical Single-Level Pincer Stenosis Causing Myelopathy: A Technical Note and Medium-term Results of a One-Session Microsurgical 360-Degree Treatment
}

\author{
Luca Papavero $^{10}$ Markus Pietrek $^{1}$ Carlos J. Marques ${ }^{2}$ Gregor Schmeiser $^{1}$
}

\footnotetext{
${ }^{1}$ Schoen Clinic Hamburg Eilbek, Academic Hospital of the Eppendorf University Medical Center - Clinic for Spine Surgery, Hamburg, Germany

2 Science Office of the Orthopedic and Joint Replacement Department, Schoen Clinic Hamburg Eilbek, Academic Hospital of the Eppendorf University Medical Center - 2, Hamburg, Germany

J Neurol Surg A Cent Eur Neurosurg 2022;83:e1.
}

Address for correspondence Luca Papavero, MD, PhD, Schoen Clinic Hamburg Eilbek, Academic Hospital of the Eppendorf University Medical Center - Clinic for Spine Surgery, Hamburg, Germany (e-mail: luca.papavero@yahoo.de).

\section{ERRATUM}

article published online December 6, 2021
The authors have informed the Publisher about a change in the presentation of the third authors' name. The DOI of the original article is: https://doi.org/10.1055/s-00411723811 (published efirst on October 11, 2021).

1. The author name "Carlos José Marques" should read as "Carlos J. Marques".

2. ORCID ID of Dr. Carlos J. Marques has been added. The ORCID is 0000-0003-3216-6382. The details have been corrected in the author field given above.
DOI https://doi.org/ 10.1055/s-0041-1740913. ISSN 2193-6315. (c) 2021. The Author(s).

This is an open access article published by Thieme under the terms of the Creative Commons Attribution-NonDerivative-NonCommercial-License, permitting copying and reproduction so long as the original work is given appropriate credit. Contents may not be used for commercial purposes, or adapted, remixed, transformed or built upon. (https://creativecommons.org/ licenses/by-nc-nd/4.0/)

Georg Thieme Verlag KG, Rüdigerstraße 14, 70469 Stuttgart, Germany 